\title{
Cellular Microparticles in Subarachnoid Hemorrhage
}

\author{
Susanne Boettinger ${ }^{1} \cdot$ Peter Lackner ${ }^{1}$
}

Received: 12 June 2015 / Accepted: 15 June 2015 / Published online: 24 June 2015

(C) Springer Science+Business Media New York 2015

Cellular microparticles (MPs) were first described by Wolf et al. in 1967 as pro-coagulant "dust" surrounding activated platelets [1]. Recently, MPs have been studied in a variety of diseases and have been recognized as important mediators of physiological and pathophysiological processes. MPs are formed by an outward blebbing of the plasma membrane of various cells with a diameter of $0.1-1.0 \mu \mathrm{m}$. During MP formation, the plasma membrane undergoes a conformational change exposing phosphatidylserine (PS) residues on the surface [2]. After shedding into the extracellular space, MPs can act as messengers carrying cell-surface proteins from the cell of origin and additional cytosolic contents including enzymes, RNA, miRNA, and DNA [3, 4]. The release of MPs occurs under stress conditions or during cell activation [3]. MP formation has been observed in cells of vascular origin (endothelial cells, smooth muscle cells) and blood cells (platelets, leucocytes, and erythrocytes). In healthy individuals, the basal number of circulating MP is low, whereas elevated levels are found in a variety of pathological conditions [4].

Endothelial MPs were shown to reflect vascular pathology in ischemic stroke as the level of MPs directly correlates with the clinical disease severity and infarct volume [5]. The data on MPs in hemorrhagic stroke is sparse [6-9]. In patients with intracerebral hemorrhage, elevated MPs were shown to be associated with outcome $[8,9]$. After subarachnoid hemorrhage (SAH), endothelial MPs are elevated in correlation with the development of cerebral vasospasm and, even more importantly, platelet-derived MPs seem to be associated with

Peter Lackner

peter.lackner@i-med.ac.at

1 Department of Neurology, Medical University Innsbruck, Innsbruck, Austria delayed cerebral ischemia (DCI) [6]. Therefore, MPs might be promising biomarker candidates for secondary complications in patients suffering from ischemic as well as hemorrhagic stroke.

In addition to this potential, MPs might in fact be involved in the pathomechanism of DCI. While DCI has been historically associated with cerebral vasospasm, it is now recognized that numerous pathways contribute to its pathogenesis [10]. The complex derangement of proinflammatory mediators and the coagulation cascade might be a vasospasm independent cause of microthrombosis leading to DCI [11]. The role of endothelial/platelet MPs in this cascade has not been investigated in SAH so far; however, cell culture studies give no doubt that stimulation by proinflammatory mediators, like TNF- $\alpha$, result in an increased release of endothelial MPs expressing tissue factor (TF) on their surface [12]. Furthermore, endothelial MPs are shortening the plasma clotting time in coagulation assays [13] and have a 50- to 100-fold higher pro-coagulant activity than activated platelets [14]. Exposure of PS not only facilitates formation of coagulation complexes (tenase and prothrombinase) but also promotes the ability of TF to initiate the coagulation cascade [15]. Recently, Simard et al. showed that infusion of low-dose heparin significantly reduced demyelination, transsynaptic apoptosis, and neuroinflammation after experimental SAH in rats [16]. The effect of heparin is pleiotropic and in the context of SAH, it could possibly antagonize pro-coagulatory MPs leading to microthrombosis [17]. In vitro data support this idea of a reduced potential of MPs to induce thrombin generation after heparin exposure [18].

In contrast to their pro-coagulatory effect, endothelial MPs also show fibrinolytic activity by cleaving plasminogen into plasmin at their surface [19]. Increasing the clearance of subarachnoidal blood has been suggested as a treatment option for SAH [20], and restoration of CSF flow and cortical 
perfusion in the early phase of experimental SAH in mice could recently be shown by this approach [21]. In this context, endothelial MP might not only have detrimental effects during SAH.

Besides their importance in coagulation, MPs seem to be involved in vascular remodeling too. Endothelial MPs were shown to express the uPA/uPA-receptor on their surface, a system that modulates the angiogenic response of endothelial progenitors in vitro [19]. In addition, MPs are exposing proteases such as metalloproteinase 9 (MMP-9) that affect angiogenesis and are important with respect to the integrity of the blood brain barrier [22]. MMP-9 mediates early brain injury in SAH by causing neuronal apoptosis through disruption of the interaction between neurons and the extracellular matrix [23] and has been shown to be associated with functional outcome following SAH [24, 25].

The complex mechanisms leading to MP formation are not fully understood. Rho-associated protein kinases (ROCKs) that regulate the actin cytoskeleton are likely to be involved. ROCK inhibitors, such as Y-27632, significantly reduce the number of MPs produced through the ROCK-dependent signaling pathway as well as eliminating the appearance of microvesicles on the cell surface [26]. The Rho/Rho-kinase pathway is considered important in the pathogenesis of sustained smooth muscle cell contraction during cerebral vasospasm after SAH and Fasudil (a ROCK inhibitor) is in clinical use in SAH patients [27, 28]. Although not yet investigated, reduced MP formation could be another effect of Fasudil conferring a clinical benefit.

In conclusion, a variety of studies suggest that MPs are involved in the pathophysiology of SAH. Although the experimental and/or clinical data in SAH is sparse, MPs could in fact be a link between the proinflammatory condition in the early phase of SAH, recently also termed "neurohemoinflammation" and delayed ischemic deficits observed after several days. Therefore, future studies on the role of MPs during SAH are of importance and could reveal potential new therapeutic targets.

\section{References}

1. Wolf $\mathrm{P}$. The nature and significance of platelet products in human plasma. Br J Haematol. 1967;13:269-88.

2. Boulanger CM. Microparticles, vascular function and hypertension. Curr Opin Nephrol Hypertens. 2010;19:177-80.

3. Dignat-George F, Boulanger CM. The many faces of endothelial microparticles. Arterioscler Thromb Vasc Biol. 2011;31:27-33.

4. Morel O, Jesel L, Freyssinet JM, Toti F. Cellular mechanisms underlying the formation of circulating microparticles. Arterioscler Thromb Vasc Biol. 2011;31:15-26.

5. Jung KH, Chu K, Lee ST, Park HK, Bahn JJ, Kim DH, et al. Circulating endothelial microparticles as a marker of cerebrovascular disease. Ann Neurol. 2009;66:191-9.
6. Lackner P, Dietmann A, Beer R, Fischer M, Broessner G, Helbok R, et al. Cellular microparticles as a marker for cerebral vasospasm in spontaneous subarachnoid hemorrhage. Stroke. 2010;41:2353-7.

7. Sanborn MR, Thom SR, Bohman LE, Stein SC, Levine JM, Milovanova T, et al. Temporal dynamics of microparticle elevation following subarachnoid hemorrhage. J Neurosurg. 2012;117:57986.

8. Huang M, Hu YY, Dong XQ. High concentrations of procoagulant microparticles in the cerebrospinal fluid and peripheral blood of patients with acute basal ganglia hemorrhage are associated with poor outcome. Surg Neurol. 2009;72(5):481-9.

9. Dong XQ, Huang M, Hu YY, Yu WH, Zhang ZY. Time course of plasma microparticle concentrations after acute spontaneous basal ganglia hemorrhage. Acta Neurol Scand. 2011;123(4):280-8.

10. Brathwaite S, Macdonald RL. (2013) Current management of delayed cerebral ischemia: update from results of recent clinical trials. Transl Stroke Res. 2014;5(2):207-26. doi:10.1007/s12975-0130316-8.

11. Vergouwen MDI, Vermeulen M, Coert BA, Stroes ESG, Roos YBWEM. Microthrombosis after aneurysmal subarachnoid hemorrhage: an additional explanation for delayed cerebral ischemia. $\mathrm{J}$ Cereb Blood Flow Metabol. 2008;28:1761-70.

12. Combes V, Simon AC, Grau GE, Arnoux D, et al. In vitro generation of endothelial microparticles and possible prothrombotic activity in patients with lupus anticoagulant. J Clin Invest. 1999;104:93102.

13. Jy W, Jimenez JJ, Mauro LM, Hoestman LL, Cheng P, Ahn ER, et al. Endothelial microparticles induce formation of platelet aggregates via a von Willebrand factor/ristocetin dependent pathway, rendering them resistant to dissociation. J Thromb Haemost. 2005;3:1301-8.

14. Sinauridze EI, Kireev DA, Popenko NY, Pichugin AV, Panteleev MA, Krymskaya OV, et al. Platelet microparticle membranes have 50- to 100-fold higher specific procoagulant activity than activated platelets. Thromb Haemost. 2007;97:425-34.

15. Wolberg AS, Monroe DM, Roberts HR, Hoffman MR. Tissue factor deencryption: ionophore treatment induces changes in tissue factor activity by phosphatidylserine-dependent and -independent mechanisms. Blood Coagul Fibrinolysis. 1999;10:201-10.

16. Simard JM, Tosun C, Ivanova S, Kurland DB, Hong C, Radecki L, et al. Heparin reduces neuroinflammation and transsynaptic neuronal apoptosis in a model of subarachnoid hemorrhage. Transl Stroke Res. 2012;3 Suppl 1:S155-65.

17. Simard JM, Schreibman D, Aldrich EF, et al. Unfractionated heparin: multitargeted therapy for delayed neurological deficits induced by subarachnoid hemorrhage. Neurocrit Care. 2010;13:439-49.

18. Ben-Hadj-Khalifa S, Hézard N, Almawi WY, Remy MG, Florent B, Mahjoub T, et al. Differential coagulation inhibitory effect of fondaparinux, enoxaparin and unfractionated heparin in cell models of thrombin generation. Blood Coagul Fibrinolysis. 2011;22(5): 369-73.

19. Lacroix R, Sabatier F, Mialhe A, Basire A, Pannell R, Borghi H, et al. Activation of plasminogen into plasmin at the surface of endothelial microparticles: a mechanism that modulates angiogenic properties of endothelial progenitor cells in vitro. Blood. 2007;110:2432-9.

20. Sasaki T, Kodama N, Kawakami M, Sato M, Asari J, Sakurai Y, et al. Urokinase cisternal irrigation therapy for prevention of symptomatic vasospasm after aneurysmal subarachnoid hemorrhage: a study of urokinase concentration and the fibrinolytic system. Stroke. 2000;31:1256-62.

21. Siler DA, Gonzalez JA, Wang RK, Cetas JS, Alkayed NJ. Intracisternal administration of tissue plasminogen activator improves cerebrospinal fluid flow and cortical perfusion after subarachnoid hemorrhage in mice. Transl Stroke Res. 2014. doi:10. 1007/s12975-014-0329. 
22. Taraboletti G, D'Ascenzo S, Borsotti P, Giavazzi R, Pavan A, Dolo $\mathrm{V}$. Shedding of the matrix metalloproteinases MMP-2, MMP-9, and MT1-MMP as membrane vesicle-associated components by endothelial cells. Am J Pathol. 2002;160:673-80.

23. Guo ZD, Sun XC, Zhang JH. Mechanisms of early brain injury after SAH: matrix metalloproteinase 9. Acta Neurochirur. 2010;(Pt 1): 63-5.

24. Chou SHY, Feske SK, Simmons SL, Konigsberg GJ, Orzell SC, Marckmann A, et al. Elevated peripheral neutrophils and matrix metalloproteinase 9 as biomarkers of functional outcome following subarachnoid hemorrhage. Transl Stroke Res. 2011;2:600-7.

25. Fischer M, Dietmann A, Beer R, Broessner G, Helbok R, Pfausler $\mathrm{B}$, et al. Differential regulation of matrix-metalloproteinases and their tissue inhibitors in patients with aneurysmal subarachnoid hemorrhage. PLoS One. 2013;8(3):e59952.

26. Antonyak MA, Wilson KF, Cerione RA. R(h)oads to microvesicles. Small GTPases. 2012;3(4):219-24.

27. Naraoka M, Munakata A, Matsuda N, Shimamura N, Ohkuma H. Suppression of the Rho/Rho-kinase pathway and prevention of cerebral vasospasm by combination treatment with statin and fasudil after subarachnoid hemorrhage in rabbit. Transl Stroke Res. 2013;4: 368-74.

28. Liu GJ, Wang ZJ, Wang YF, Xu LL, Wang XL, Liu Y, et al. Systematic assessment and meta-analysis of the efficacy and safety of fasudil in the treatment of cerebral vasospasm in patients with subarachnoid hemorrhage. Eur J Clin Pharmacol. 2012;68(2):131-9. 